\title{
UNA MIRADA CULTURAL A LAS ÉLITES POLÍTICAS EN LOS PRIMEROS PASOS DEL ESTADO CONSTITUCIONAL
}

\author{
Pedro Carasa \\ Universidad de Valladolid
}

\section{RESUMEN}

En la primera parte se hacen dos propuestas metodológicas para el análisis histórico de las élites políticas. La primera se refiere a la necesidad de una perspectiva cultural para poder comprender las élites isabelinas, y la segunda expone las correcciones de la perspectiva temporal (presentismo, anacronía, teleología) que conviene adoptar para estudiar este primer periodo decimonónico. En la segunda parte se analizan los primeros pasos del Estado constitucional durante los años treinta del siglo XIX como una deficiente escuela de cultura política para las élites. La hipótesis de trabajo sostiene que la vulnerabilidad del sistema constitucional y la difícil construcción del Estado dificultaron la formación de las élites. Que el aprendizaje de la nueva ordenación territorial no permitió a las élites situarse bien en los nuevos espacios políticos. Que la precariedad del parlamentarismo no permitió a las élites madurar en la cultura de la representación. Que la insegura exploración de las élites sobre los ámbitos de sociabilidad política les impide construir partidos políticos.

\section{Palabras clave:}

Historia cultural de la política, Elites, Primeros pasos del Estado constitucional, Regencia, Dificultades en la construcción del Estado, Cultura de la Representación, Ordenación política del espacio.

\section{ABSTRACT}

In the first part are two methodological proposals for the historical analysis of the political elites. The first relates to the need for a cultural perspective in order to understand the Elizabethan elite, and the second describes the correction of the time perspective (presenteeism, anacronía, teleology) to be undertaken to study this first period nineteenth century. The second part discusses the first steps of the State Constitution during the thirties of the nineteenth century as a poor school for the elite political culture. The working hypothesis argues that the vulnerability of the constitutional system and the difficult construction of the state hindered the 
formation of the elite. The learning of the new spatial not allowed elites placed well in the new political spaces. The precariousness of parliamentarianism not allowed to mature in the elite culture of representation. Que la insecure exploration of the elites on the areas of social policy prevents them from building political parties.

Key Words:

History cultural politics, Elites, First Steps of the State Constitution, Regency, Difficulties in the construction of the State, Culture Representation, Policy management space.

\section{Nuevos PUNTOS DE VISTA PARA OBSERVAR LA CUlTuRa POLÍtica de LAS Élites DECIMONÓNICAS}

\section{Una nueva visión cultural}

\section{La perspectiva cultural en el análisis de las élites decimonónicas}

Se imponen dos pasos cruciales en la consideración de las élites en el momento actual de la historiografía española: transitar de la visión material a la comprensión cultural del poder y pasar de la prosopografía sociológica a la microbiografía antropológica y análisis de la cultura política de las élites ${ }^{1}$. Parece conveniente, para empezar, contrapesar el exceso sociológico de la prosopografía con planteamientos antropológicos, descender en algunos casos concretos al análisis microbiográfico, destacar el individuo sobre la colectividad. Es necesario también superar ya el análisis de la estructura socio-económica del poder para adentrarse en la cultura política del poderoso como sujeto consciente. Este análisis cultural se fija en aspectos vinculados a las actitudes, comportamientos y gestos de los poderosos, que antes nos han pasado desapercibidos.

No entraremos ahora en los aspectos culturales menos políticos de la capacidad de atracción que ejerce la imagen de la persona y la familia de la élite, como son la sociabilidad informal y cotidiana del poderoso, la apariencia social de su persona expresada en ritos personales, familiares y sociales, el valor simbólico de la familia que se cultiva en las comunidades locales con la ostentación de escudos solariegos, casonas, palacetes, las manifestaciones de liderazgo social, de excelencia de un miembro de la comunidad, de superioridad ética y estética sobre los demás ${ }^{2}$. No abordaremos tampoco lo que significa la inversión en capital simbólico asistencial, aprovechando el enorme caudal de prestigio social y de rentabilidad política con que estaban asociadas las actividades y representaciones sociales éticas y religiosas ${ }^{3}$.

Para nuestro propósito conviene fijarse ahora sobre todo en los aspectos culturales propios de los significados y comportamientos políticos, como la imagen y percepción de la representación y del cargo de las élites en los ámbitos locales, el cultivo de actos públicos bien medidos, gestos de proximidad, mediaciones de conflictos, soluciones de problemas cotidianos, gestiones ante el poder central, etc. Nuestro viejo concepto de movilización política ha estado demasiado marcado por los paradigmas clásicos de la manifestación pública y colectiva, por la

\footnotetext{
${ }^{1}$ Estas ideas sobre la historia cultural de las élites fueron presentadas por nosotros y serán publicadas en el Secondo Convegno Internazionale di Studi Italo Spagnoli. Le Elites in Italia e in Spagna (1850-1922), en Verona, en marzo de 2006, en una ponencia titulada Las élites políticas españolas en el parlamento.

${ }^{2}$ Este planteamiento cultural en aspectos no políticos lo hemos tratado también la en ponencia al VI Congreso de la Asociación de Historia Contemporánea celebrado en Vitoria el 22 de setiembre de 2007, en torno a Movimientos sociales y élites, de próxima publicación.

${ }^{3}$ Sobre este particular hemos reflexionado en las reuniones de trabajo de la red temática europea COAST 34, sobre Trabajo, género y familia en la Asistencia social, celebrado en Barcelona en Junio de 2007.
} 
existencia de los partidos políticos tal como hoy los concebimos, y no hemos sabido percibir como verdaderos actos de movilización otros gestos no menos importantes, mecanismos cotidianos e informales de participación política, más humildes pero efectivos, aunque no se atengan a las fórmulas tópicas de mítines, propaganda electoral, campañas, o compra de votos. Tampoco conocemos los imaginarios populares sobre la representación parlamentaria, el conjunto de significados que se atribuyen a un diputado o senador, y las actitudes y gestiones que se esperan de él. Una concepción antropológica e interactiva del poder debería ocuparse de la moral y la ética pública con que la mentalidad popular evalúa a las élites. Hay que conocer el impacto político en la aceptación popular de la élite que producen los usos de los valores tradicionales, de la historia, de la costumbre, de la moral, del interés, de la deferencia, del respeto, o de la tradición familiar.

En este momento histórico de los años treinta del siglo XIX, cuando aparecen los grandes cambios en la naturaleza y titulares de la propiedad, es importante asimismo descubrir los códigos éticos que rigen la gestión de la riqueza en relación con la política, cómo valora el pueblo los bienes materiales en un político. La propiedad, tanto vista desde el sistema como desde los votantes, era entonces, más que un adorno necesario para la imagen, una conditio sine qua non para el poder, como se deducía espontáneamente de la teoría de la plutocracia. Los planteamientos actuales de economía moral pueden explicar cómo se forma en el argumentario e imaginario popular el valor de la propiedad, el sentido del plutócrata, del propietario líder y del honrado contribuyente; es pertinente descubrir qué papel juegan estas imágenes y argumentos a la hora de construir una elite política. No debemos caer en el viejo defecto de aplicar anticipadamente la valoración negativa regeneracionista que subyace aún entre nosotros, aquella que condenaba moral y éticamente al cacique propietario como explotador y corrupto, y tratar de descubrir cómo percibe el pueblo la máxima de que el representante que mejor defiende los intereses locales es el potentado local. Hay que replantearse desde la historia de la moral, cómo cambian las pautas éticas en relación con una situación de engaño o corrupción política, la ética política popular decimonónica es una desconocida para nosotros, no acabamos de comprender bien cómo percibían ellos lo que llamamos hoy manipulaciones electorales, hay otros códigos anteriores a las concepciones morales clásicas del caciquismo y la "corrupción" política que conviene tener en cuenta y que son desconocidos aún entre nosotros.

Sobre todo, nos interesan los grandes ejes en torno a los que se construye la cultura política de las élites en los primeros pasos del Estado constitucional: el concepto de Estado, la relación entre lo general y lo particular, el sentido de lo público y lo privado, la articulación de los poderes central, provincial y municipal, la cultura local. Es el marco histórico oportuno para analizar la creación del espacio como una realidad política, cuando se estaban diseñando y aplicando por primera vez organizaciones territoriales para articular los espacios estatales y se estaban definiendo y cargando de sentido político los espacios de la comunidad local. Ahora es cuando tiene un gran interés cultural el proceso en el que aprenden y ensayan diversas maneras de representar el territorio físico en la organización electoral del Estado. Entonces no tenían tan perfectamente separados como nosotros los conceptos de lo público y lo privado, no estaban criminalizados los intereses particulares como después han transmitido los paradigmas de la historia económica y social clásica, eran muy importantes para ellos los llamados intereses provinciales, los intereses de los pueblos o municipales ${ }^{4}$.

En la consideración de las élites no hemos tenido en cuenta hasta ahora una serie de mediatizaciones de la vida pública y la acción política que eran anteriores y más fuertes que las de la constitución, el Estado o el parlamento mismo. Importa comprender cómo se elabora y va acunándose el concepto de representación, su capacidad de diferenciar entre los derechos civiles y políticos, el sentido incipiente de ciudadanía, tan ajeno a la vieja cultura y cuya introducción

\footnotetext{
${ }^{4}$ Próximamente aparecerá un número monográfico de la Revista Alcores, coordinado por nosotros, comparando varios estudios de caso internacionales, dedicado a Lo local en la cultura política del siglo XIX; en él se valorará este aspecto más inmediato de la cultura local en el proceso de modernización de la cultura política de las élites en el siglo XIX.
} 
fue extraordinariamente costosa y lenta si la consideramos desde nuestra manera de entenderla. Se estaba inventando lo que era la función de un parlamentario, se están explorando los cometidos y ritos de un diputado. Como en un laboratorio experimental, se está descubriendo qué papel se le asigna inicialmente al parlamento, qué prácticas tanto parlamentarias como extraparlamentarias, eran habituales en la percepción popular de un diputado o senador. En cuanto a la práctica electoral, sabemos mucho de sociología y artimañas caciquiles, pero desconocemos si inicialmente el sentido de participación que imperaba en la sociedad y en las élites coincidía realmente con la interpretación "democrática" que nosotros le asignamos a posteriori. Es preciso ahondar en el sentido transaccional del voto, hay que dejar de despreciar los favores como meras corruptelas y empezar a apreciarlos como rudimentarias formas de participación y conciencia de los propios derechos.

\section{La etapa fundacional isabelina ofrece más posibilidades culturales}

Como advierte M. C. Romeo, aún subsisten verdaderos vacíos historiográficos sobre el mundo político isabelino. Está pendiente -decía- el estudio de la difícil organización y construcción del Estado liberal, así como una investigación sistemática sobre la composición sociológica del Parlamento, o el papel efectivo del Senado. Pero más que unos temas concretos, la época de Isabel II exige perspectivas analíticas y enfoques interpretativos renovados, que sean más específicos para el periodo que procedentes de otras etapas cronológicas. En este sentido, una mayor atención a los elementos culturales como conformadores de la actuación de los sujetos históricos y de identidades colectivas haría más rica y dinámica nuestra comprensión de la política y de la sociedad del reinado de Isabel $\mathrm{II}^{5}$.

En efecto, los dos primeros tercios del siglo XIX constituyen el momento más apasionante y creativo en que se echan las bases de la nueva cultura política contemporánea, y desde esta perspectiva son mucho más apropiados e interesantes que la Restauración para ensayar en ellos análisis de tipo cultural. En el periodo que va de 1808 a 1874, particularmente entre 1833-1844, es cuando, bajo la persistencia de numerosas herencias de la vieja cultura política que se resisten a morir, se acuñan en su versión moderada y doctrinaria más influyente los grandes conceptos, los significados, los argumentarios y las legitimidades del mundo político contemporáneo. Sólo tiene uno que releer la historia de los conceptos más elementales de liberalismo, burguesía, clase, parlamento, ciudadanía, cortes, individualismo, clases medias, elección, censitario, sufragio, igualdad, libertad, nación, soberanía, política, propiedad, público/privado, y comprobar cómo la mayoría de estos conceptos nacen entre nosotros en la segunda mitad del XVIII, se acunan y consolidan entre 1808-1874, pero es en la década de los treinta cuando comienzan a ponerse en práctica de manera titubeante y exploratoria. Precisamente en el primer tercio del XIX nacen los conceptos habituales al analizar las élites, como Estado constitucional, representación, diputado, distrito, elector, partido político ${ }^{6}$.

Y son justamente las élites intelectuales y políticas de este momento las que realizan en esta dirección tres grandes esfuerzos para acuñar todos estos conceptos: reactivo, creativo y aplicativo. El esfuerzo reactivo fue necesario primero para despegarse de las referencias de su vieja cultura política heredada del Antiguo Régimen, que estaba presente en el subconsciente de las élites y en las actitudes más primarias de las instituciones y los órganos políticos. El segundo esfuerzo fue el creativo, centrado en construir esos conceptos y llenarlos de significados y legitimidades, seguramente que impulsados básicamente por la influencia francesa, tanto del afrancesamiento ilustrado inicialmente, como de la influencia revolucionaria después, como finalmente del influjo doctrinario. Y el último esfuerzo aplicativo, no menos ingente, fue la pragmática invención de ponerlos en práctica, con las incertidumbres propias de todo momento

\footnotetext{
${ }^{5}$ M. C. Romeo, "La política de Isabel II: comentario bibliográfico", en Ayer, 29 (1998)217-222; D. Caro, El primer liberalismo en Andalucía. Cádiz, 2006.

${ }^{6}$ J. Fernández Sebastián - J.F. Fuentes, Diccionario político y social del siglo XIX español. Alianza. Madrid, 2002.
} 
creativo que está abriendo camino y con la pasión propia de los exploradores que experimentan, casi en un laboratorio político, las nuevas instituciones, conceptos y comportamientos.

Por esta razón, tenemos planteada una nueva serie de proyectos de investigación dedicados a la España isabelina, tanto a escala española como regional, y con nosotros, hay otros equipos que están preparando nuevos proyectos o que avanzan algunas conclusiones de su trabajo $^{7}$. No me resisto a anunciar aquí que ya está en marcha uno de los proyectos más ambiciosos que sobre las élites parlamentarias se haya realizado en el sur de Europa, un gran convenio de las Cortes Españolas que, bajo un equipo directivo de especialistas reconocidos, ha movilizado a más de 45 universidades españolas, para establecer una red permanente de estudios de historia parlamentaria, comenzando por un Diccionario Biográfico de Parlamentarios españoles que incluirá más de 45.000 entradas, seguido de publicaciones, reuniones científicas, doctorados y cursos de postgrado en toda España.

\section{Algunas correcciones de la perspectiva temporal con que hemos analizado las élites Efectos de algunas distorsiones temporales como el presentismo, la anacronía y la teleología}

Los historiadores debemos ser muy cuidadosos con el factor tiempo en la construcción de nuestro discurso. Hasta ahora, en los paradigmas de la historia social y política clásicas, han sido muy socorridas las distorsiones del presentismo o la anacronía. Pero a partir de la historia cultural, hay que poner más atención a la contaminación teleológica del discurso sobre el pasado, porque lo elaboramos conociendo el final de la historia, juzgando los hechos desde una perspectiva totalmente diferente a la de los protagonistas, porque enjuiciamos los procesos después de conocer el resultado posterior de su evolución. Nosotros contemplamos la película sabiendo ya su desenlace, y esto puede hacernos creer que la vemos con mejores ojos y que seremos más capaces de descubrir mejor sus contenidos. Sin embargo, los protagonistas no conocen el final, es más, su proceder sólo se comprende porque no conocen el final; la mayoría de las veces los sujetos de la acción no actuarían como lo hacen si conocieran cómo iba a acabar, incluso no sería comprensible para nosotros su proceder si presupusiéramos que ellos conocen el final. Este símil puede ayudarnos a entender por qué, si no cuidamos nuestra perspectiva, los historiadores podemos contaminar el discurso histórico que construimos y falsear las actitudes e intenciones de los protagonistas reales.

Por ejemplo, abundan en nuestra terminología conceptos como defecto, fracaso, desviación, deficiencia, error, corrupción, etc. que están construidos desde nuestra experiencia del final de la historia, desde el conocimiento de los pasos sucesivos que se han producido después y desde la constatación del resultado último del proceso. Cuando analizamos las élites en sus primeros momentos de la construcción del Estado constitucional les estamos aplicando, sin darnos cuenta, incluso a veces queriendo evitarlo sin conseguirlo, el modelo de su acabado final democrático y actual. Y nada más lejos de su realidad política, que caminaba a ciegas y sin tener delante todo el recorrido posterior.

\section{Hemos tallado a las élites decimonónicas con patrones actuales}

El primer error, pues, consiste en comparar subconscientemente a las élites de la primera mitad del siglo XIX con los modelos democráticos actuales, en adjudicarles hábitos de cultura

\footnotetext{
${ }^{7}$ En nuestro caso iniciamos el segundo año de un proyecto sobre las élites isabelinas en Castilla y León, sabemos que sigue su curso otro en Andalucía y Levante que ya ha hecho su presentación en Ayer, 61, La Representación política en la España Liberal. Son de destacar las investigaciones sobre elites en el marco de la Universidad de Cádiz, de los profesores Jesús Manuel González Beltrán, Diego Caro Cancela, María Dolores Fuentes Bajo y Juan Ramón Cirici Narváez, como se ha puesto de manifiesto en la celebración de este IX Encuentro de Primavera de la Universidad de Cádiz en El Puerto de Santa María, bajo el título "Las Elites y sus manifestaciones de Poder", junto a la publicación del posterior monográfico de la revista Trocadero.
} 
política que presuponemos tendentes a unos procesos posteriores que eran desconocidos para ellos. Y debemos evitarlo, sobre todo cuando pretendemos adoptar una óptica de historia cultural, es decir, cuando pretendemos observar la actuación de los sujetos históricos conscientes desde abajo y cuando aspiramos a descubrir los contenidos de los discursos y significados construidos en otro presente distinto al nuestro. Frecuentemente les imputamos déficits de representación tal como la entendemos nosotros hoy, les achacamos hábitos de corrupción con las reglas morales y de ética política posterior, les acusamos de no haber alcanzado niveles de calidad democrática y virtudes de cultura política que ha costado más de un siglo alcanzar y consolidar.

De alguna manera, en los viejos conceptos tanto de revolución como de modernización, estaba implícito este defecto de calificar de fracasados, inmaduros, o desviados ciertos comportamientos que no estaban acordes con una determinada teleología hacia la que debía orientarse el acto histórico. En este sentido, la historia cultural ofrece más posibilidades de corregir estas deformaciones anacrónicas y teleológicas tan propias de la historia social clásica. Porque nos permite posicionarnos en la mente y actitud del sujeto consciente, en su momento histórico, haciendo el esfuerzo de dar por sabido sólo lo que él sabe y no lo que sabemos nosotros. En esta dirección, es justamente la historia de los conceptos y la historia de los discursos, significados y representaciones, la que más nos puede ayudar a corregir estos estrabismos propios de nuestra condición de historiadores.

\section{Hemos aplicado a las élites isabelinas el cliché de la Restauración}

En la historiografía española puede advertirse otro problema de cierto desenfoque cronológico, porque venimos estudiando las élites desde lo más reciente a lo más antiguo. A veces nos obsesionamos con la búsqueda de causalidades y orientamos forzadamente nuestras pesquisas en busca de antecedentes de efectos posteriores que no estaban en las previsiones ni en la consciencia de los sujetos anteriores. Este defecto ha de cuidarse en casos particulares como el mío $^{8}$, que hemos comenzado el estudio de las élites desde el siglo XX. En estas condiciones, puede resultar desenfocada la mirada a las élites de la primera parte del siglo XIX, después de haberse enfrascado en los debates sobre las deformaciones de su cultura política en la Restauración. La obsesión del caciquismo puede conducirnos a ciertos errores de perspectiva y trasladar al análisis del primer momento fundacional del Estado constitucional problemas artificiales que no eran propios de su etapa natural de desarrollo. También hay que hacer un esfuerzo por no contaminar la etapa isabelina con los debates propios de la Restauración, es preciso superar esta etapa, no sólo cronológica, sino también metodológicamente.

Tal vez esta concentración en las élites de la Restauración haya sido una de las causas por las que el tema de las élites se ha atascado en un cierto cansancio y se ha enredado demasiado con el debate sobre el caciquismo. Este espacio cronológico venía pesadamente lastrado por debates inacabables de la historia social clásica, que han contaminado de clasicismo excesivo el manejo del nuevo concepto de elites y no han permitido avanzar en la dirección apetecida de historia cultural. Este debate no sólo ha contaminado el manejo del concepto de elites, sino también ha pervertido otros nuevos instrumentos que se han desnaturalizado en su contacto, como el de nueva historia política que se ha deslizado hacia la reedición de la historia tradicional. Y, sobre todo, ha limitado el manejo de la herramienta de la cultura política que, tal como se ha aplicado, ha tenido mucho más de política que de cultura. Por ejemplo, toda la construcción cultural de la élite parlamentaria como puente intermediario entre la cultura de la deferencia y la cultura de la participación, se ha agotado finalmente en otra explicación más del debate clásico de la historia social sobre la naturaleza política o económica del caciquismo, sin valorar que se trata de una realidad básicamente cultural. Esta explicación se ha servido de los mismos viejos esquemas interpretativos clásicos, no ha girado hacia procesos y discursos de

\footnotetext{
${ }^{8}$ P.Carasa (Dir.), Elites Castellanas de la Restauración. I. Diccionario biográfico de parlamentarios castellanos y leoneses, 1876-1932. y II, Élites Castellanas de la Restauración. Una aproximación al poder político en Castilla. Salamaca, 1997.
} 
naturaleza cultural. Así ha sucedido cuando nos hemos entretenido en exceso sobre la cuestión de si la influencia de la élite es de naturaleza económica o política, y con ello hemos tapado las enormes posibilidades de descubrir los profundos resortes culturales que laten en ella.

\section{Las élites isabelinas no sólo han de ser vistas desde abajo, sino también desde atrás}

Hay, además, otra razón específica para cambiar la perspectiva en el caso de los primeros pasos del Estado constitucional, y es la conveniencia de la mirada hacia atrás. Toda construcción de conceptos arranca de la cultura tradicional que pretende superar, los materiales con los que está construida la cultura política de las élites de la primera parte del XIX están extraídos de la cantera del acervo cultural del Antiguo Régimen como punto de partida. Muchas veces los nuevos conceptos de la cultura política liberal no se edifican con materiales nuevos, sino partiendo de presupuestos anteriores, aunque no sea más que para contradecirlos o superarlos. Acabamos de señalar que la mayoría de los conceptos del mundo electoral, parlamentario, del Estado liberal y la acción política de las élites, se acuña en la primera mitad del XIX, pero casi todos nacen antes, más en concreto, en la última etapa de la Ilustración. Y esto no es sólo una cuestión cronológica, sino que es una cuestión de contenido en la historia de los conceptos, en el sentido de que la mayoría de los significados conceptuales se construyen a partir de la superación de viejos conceptos contra los que hay que luchar o cuyos defectos tratan de erradicar.

Así la mayor parte de los significados de la última ilustración o del primer liberalismo inician su andadura a partir de la oposición a contenidos semánticos de los paradigmas modernos, o contra imaginarios de antiguo régimen que había que destruir para luego reconstruir el nuevo significado. Como se ha demostrado para la historia del concepto sociedad, que según los especialistas está construido casi frontalmente contra el imaginario social moderno y para superar sus dos limitaciones más importantes (sacralización e individualismo), así puede suceder con la mayoría de los significados sociales y políticos que se solapan durante la primera parte del XIX con la introducción de la nueva cultura liberal (representación, elección, constitucional, parlamentario, diputado, ejecutivo, provincia, ayuntamiento, etc. son conceptos que están en buena medida orientados a superar situaciones anteriores, y se ven obligados a pensarlos y definirlos con referencias y presupuestos antiguos).

Por eso la primera mitad del siglo XIX resulta un escenario particularmente interesante para el análisis cultural de la acción de la élite, porque sólo desde una perspectiva cultural seremos capaces de percibir esos significados y simbolismos heredados y su fusión o disolución con la cultura siguiente. Ahora bien, sólo alcanzaremos este objetivo si nos aproximamos a este periodo gaditano e isabelino, no con la cabeza ahormada desde los presupuestos de la cultura democrática actual, ni con el pensamiento puesto en las polémicas de la Restauración, sino con la mente virgen, como ellos la tenían, sólo condicionada por el cuarteamiento de la cultura política del Antiguo Régimen. Y en este sentido, debemos reconocer que los contemporaneístas tenemos abandonada la cultura política tradicional y el imaginario social moderno como punto de partida y como cantera de valores, símbolos y significados a la hora de estudiar la construcción de los significados, conceptos y comportamientos de la acción de las élites. Este encuentro científico puede ser un buen escenario para superar esta limitación, puesto que analizamos las élites transversalmente a lo largo de diferentes áreas de conocimiento, espacios de aplicación y cronologías de desarrollo.

Por eso Cádiz resulta un escenario particularmente interesante para el análisis cultural de la construcción de la élite política. Un punto de intersección de dos siglos decisivos e intercomunicados como fueron el XVIII y el XIX, un ámbito en que se cruzan la modernidad y la contemporaneidad, un espacio en que se encuentra la cultura americana y la española separados de manera incomprensible por burocracias académicas. En este sentido, tenemos una enorme laguna de conocimiento sobre la generación de 1808 y todo el mundo conceptual gaditano, tan entroncado por otra parte con la mano larga de la Ilustración que penetra y subsiste en buena parte del XIX. Aunque experimente fracturas y discontinuidades, el discurso moderado 
postrevolucionario se construye de alguna manera a partir de y contra el primero. Tenemos abandonada esta parcela de la cultura política tradicional y el imaginario social moderno como punto de partida y como cantera de valores, símbolos y significados a la hora de estudiar la construcción de los significados, conceptos y comportamientos de la acción de las élites. Pagamos tributo a una separación de áreas que nos impide relacionar dos mundos culturales conectados.

De todo este periodo, sin embargo, nosotros hemos elegido la década de los treinta, porque consideramos que probablemente es la etapa más influyente en la primera aplicación práctica del modelo gaditano y la más efectiva en la formación postrevolucionaria de la cultura política de las élites, ahormada por la cultura moderada y doctrinaria en España. En la etapa de las regencias, entre 1833-40, se contrasta el modelo revolucionario gaditano y del trienio con la dura y resistente sociedad española y se comprueban las disfunciones que generaba la aplicación de los modelos legislativos de 1812 y de 1822. Tras comprobar las incompatibilidades que presentaba entre nosotros el modelo francés de la revolución, se vuelve en un corto periodo de tiempo al afrancesamiento ilustrado, y se opta finalmente por el otro modelo francés del doctrinarismo. En este contexto doctrinario es en el que se comienza a crear un nuevo patrón de cultura política entre las élites españolas, sin duda el más duradero e influyente, que hemos convenido en llamar postrevolucionario, y que cristalizará luego en el moderantismo isabelino. Por ello, nos centraremos en los problemas que plantean en España estos primeros pasos del Estado constitucional español entre los años $1833-1840^{9}$, y en torno a ellos analizaremos los grandes ejes constructores de la cultura política de las élites.

\section{LOS Difíciles PRIMEROS PASOS DEL ESTADO CONSTITUCIONAL COMO ESCUELA DE CULTURA POLÍTICA PARA LAS ÉLITES}

\section{A modo de hipótesis de trabajo}

Quisiéramos adelantar una especie de hipótesis de trabajo según la cual el periodo de las regencias fue una inadecuada y rudimentaria escuela de cultura política para las élites españolas. Parece que las condiciones que el proceso de formación del Estado constitucional ofreció a las élites fueron poco propicias para la maduración de su cultura política y para la cohesión de sus propios grupos. El reto que debían afrontar las élites políticas, particularmente las parlamentarias, en este periodo, consistía en abandonar los viejos hábitos y legitimidades con que las anteriores élites políticas participaban en la vida del Estado absolutista en calidad de consejeras del monarca, gracias a la función áulica estamental. Por otro lado, debían aprender la nueva función que les asignaba el Estado constitucional, en el que ya no eran meros consultores y transmisores pasivos del poder del monarca, sino actores principales del poder del Estado, sujetos activos de poder en calidad de intermediarios entre los poderes legislativo/ejecutivo y la sociedad.

Este tránsito de sistema político requiere en las élites un largo aprendizaje de conceptos teóricos y hábitos prácticos que se refieren a varios aspectos vertebrales de la nueva cultura política. Ante todo, nace una nueva manera de ver la Corona y relacionarse con el monarca, del que ya no eran meros consejeros, como decía la vieja función estamental áulica atribuida a la nobleza, sino que debían asumir la nueva misión de posibles críticos y detractores del rey en calidad de representantes de la soberanía de un Estado que necesitaba recuperarla arrancándosela al monarca. A diferencia de la claridad con la que las élites francesas percibieron el final de los

\footnotetext{
${ }^{9}$ Utilizamos conscientemente esta expresión de "los primeros pasos del Estado constitucional", porque es exactamente el título del libro de Alejandro Nieto, Los primeros pasos del Estado constitucional. Ariel Derecho. Barcelona, 1996, en el que nos basamos para identificar los grandes problemas que se experimentaron durante este proceso en España. Nos ha servido de punto de partida la valoración crítica que hace de esta construcción del Estado constitucional.
} 
privilegios de la monarquía, desgraciadamente, esta lección no pudieron aprenderla las élites españolas, ni en la etapa gaditana que se convirtió en una escuela de rehabilitación monárquica, ni siquiera en el Trienio cuando los pequeños brotes de control monárquico fracasaron, ni particularmente durante las regencias, cuando el debate entre Estado y monarquía acabó en la sumisión de aquél a la moderación y arbitraje de ésta. En la cultura política de las élites españolas quedó un poso heredado de absolutismo que, en la pugna por la titularidad de la soberanía entre el rey y el Estado, colocó a la monarquía en una clara posición de ventaja. Comprobaremos cómo, especialmente en la experiencia política de la regencia, este aprendizaje sobre la ubicación de la Corona en el sistema liberal generó en las élites una cultura más monárquica que estatal.

En segundo lugar, las élites tenían que cambiar la concepción misma del Estado, e incorporar a sus experiencias lo que se llama el "sentido de Estado", la idea de un Estado constitucional soberano, fuente y centro de la vida política, gestor de la sagrada representación y participación ciudadana, garante de los derechos individuales y titular de los servicios públicos debidos a la sociedad. Pero, también a diferencia de las élites francesas que habían aprendido esta lección mediante la fuerte experiencia del jacobinismo durante la revolución, las élites españolas no consiguieron armarse de un sentido de Estado fuerte. Es verdad que en la etapa gaditana y veinteañista se impuso el centralismo y una cierta cultura política de que el poder discurría por una corriente descendente por la pirámide desde la cúpula del Estado a la base municipal. Pero a partir de las regencias, las rebeliones provinciales, municipales y junteras acabaron debilitando esa corriente y rompiendo en pedazos el sentido de Estado. Las élites españolas tuvieron una muy limitada educación estatal, dada la debilidad teórica de la concepción del Estado, pero, sobre todo, dada la vulnerabilidad práctica de su puesta en funcionamiento.

El tercer capítulo en este programa de aprendizaje de la nueva cultura política se refiere a la definición de los derechos fundamentales y la primera experiencia de la ciudadanía. Las exploraciones titubeantes de reconocimiento de estos derechos no permitieron consolidar en la mentalidad de las élites este apartado como una base estable e indiscutible de su cultura política. Les costó, en primer lugar, al distinguir entre derechos civiles y políticos, reconocer éstos como derechos fundamentales. Y más aún les costó adquirir el hábito de su aplicación y respeto, que estuvo ausente de su vida política particularmente durante la regencia. Todo ello produjo como resultado una muy precaria vivencia social de la ciudadanía, una falta de sentido cívico y una ausencia de responsabilidad ciudadana que desgraciadamente ha pesado persistentemente en las élites y la sociedad españolas.

Pero este programa de nueva cultura política constaba de más lecciones, que se referían a la diferente organización y a las nuevas actitudes que exigía el marco del Estado constitucional. Estamos hablando de la adaptación que la élite debía conseguir a la inédita organización política del espacio y de la desconocida manera de situarse entre el Estado y la sociedad gracias al concepto y la experiencia de la representación. Por lo que se refiere a la organización territorial del Estado constitucional, las élites españolas descubrieron en estos años el nuevo sentido político de los espacios articulados en niveles dentro de la pirámide del Estado, dando un peso prioritario a lo provincial y local. Consiguieron una ordenación teóricamente aceptable, menos racionalista que la francesa aunque mejor adaptada a la circunstancia española, pero el aprendizaje y el primer uso que hicieron las élites de estos espacios políticos no contribuyeron a reforzar el Estado, sino que más bien consiguieron desarticularlo mediante actitudes violentas y poco respetuosas con el sistema constitucional. Sin embargo, imprimieron un carácter local a su cultura política que fue muy eficaz y tuvo una gran influencia en el futuro. Probablemente este aprendizaje espacial tuvo algunos efectos beneficiosos en su cultura política, la cultura de la provincia, la cultura del distrito, la cultura municipalista, la cultura juntera, han estado muy presentes en la cultura política española posterior, pero también pudo causar consecuencias negativas sobre la débil articulación estatal y las reiteradas agresiones a la ordenación constitucional que desde estos ámbitos se produjeron. 
Con relación a la cultura de la representación, un asunto bastante más sutil y difícil de aprehender, da la impresión, como hipótesis a falta de confirmar por los escasos estudios disponibles, de que la experiencia de las élites en estos años tuvo una sobredosis de la representación local y un déficit de la estatal. Desapareció pronto aquella idea gaditana de que cada diputado representaba a toda la nación, y se impuso, particularmente durante la regencia, el localismo y el censitarismo que vinculaba a las élites a unos territorios concretos y unos intereses particulares muy limitados. Estamos tocando con este tema fibras tan sensibles y complejas como la formación del sentido de lo público frente la privado, la preeminencia del valor general sobre el particular, que en la cultura política de las élites no se generalizará hasta el reformismo social de principios del siglo XX. En relación con este mismo asunto de la representación, hay que valorar el impacto que produjo en las élites el concepto y el manejo de las elecciones, la valoración y el uso del voto, la gestión de los espacios electorales y la actitud y actuación de estas élites en el parlamento. La primera impresión, tal como se vivieron estas experiencias en los momentos iniciales del Estado constitucional, es que no contribuyeron a inculcar en las élites el juego limpio electoral y el respeto por el voto ciudadano tal como hoy lo entendemos, ni comprendían una actividad parlamentaria exenta de las servidumbres de la vieja cultura política de la deferencia, que comprendía el voto al tiempo como favor y como participación.

Una mención aparte merece el reto de explorar la nueva sociabilidad política, es decir, el importante aprendizaje de lo que significaba una facción, un club, un grupo de notables, un partido político. Hay que ser conscientes de que estamos en un momento en que está por descubrir la manera de agruparse en estos instrumentos que hoy nos parecen básicos de la participación en el Estado constitucional. No habían funcionado los partidos políticos prácticamente hasta los años treinta, y durante las regencias se está haciendo camino al andar en este asunto. La situación es especialmente inquietante para las élites, que deben aprender a superar el hábito individual de la vieja cultura política y entrenarse en la nueva sociabilidad de grupo, de partido, de facción en que se organizaba la participación del Estado constitucional. Nos quedan muchas preguntas sobre este proceso inicial de formación de los partidos políticos y su impacto en las élites. Cuáles eran los signos de identidad de estos grupos de notables, qué papel jugó en ese proceso de identificación y polarización de los grupos políticos la ideología, los matices que tenían sobre los grandes conceptos del sistema constitucional, o si todo fue mera estrategia de acceso al poder, simples agrupaciones de defensa de los intereses más inmediatos. Y sobre todo, queda pendiente responder al gran interrogante de qué papel jugaron estos grupos de notables en promover la participación de la sociedad en la cosa pública. Todo apunta en la dirección de que aún no hemos descubierto una terminología y un bagaje conceptual capaz de comprender y expresar la sociabilidad política de este momento. Seguimos describiendo con términos y conceptos posteriores y anacrónicos la realidad de los partidos en la regencia. Se trataba sin duda de una realidad muy precaria, no sabemos siquiera si era de la misma naturaleza que los partidos posteriores. Estamos demasiado acostumbrados a interpretar el pasado a la luz de la evolución posterior y a veces con este ejercicio desnaturalizamos la realidad histórica en sí misma. Se hace preciso un esfuerzo de teoría cultural y de destreza metodológica para comprender una realidad tan informal y desconocida como eran los grupos de notables ${ }^{10}$, y tratar de extraer con imaginación todas las ricas posibilidades de enfoque cultural que tienen estas primeras experiencias de sociabilidad política.

La misma inestabilidad y vulnerabilidad del Estado no permitieron consolidar sagas estables que reforzaran los entronques generacionales y pudieran otorgar a las élites alguna

\footnotetext{
${ }^{10}$ Disponemos, es verdad, de los pioneros e importantes estudios para el ámbito valenciano de Isabel Burdiel, La política de los notables. Moderados y avanzados durante el Régimen del Estatuto Real (1834-1836). IVEI, 1987, Valencia. ID.(ed.), "La política en el reinado de Isabel II". Ayer , no 21 (1998). ID. y Pérez Ledesma, Manuel (Coord.), Liberales, agitadores y conspiradores. Biografías heterodoxas del siglo XIX. Madrid, Espasa-Calpe, 2000. M.Cruz Romeo y otros, Entre el orden y la revolución. La formación de la burguesía liberal en la crisis de la monarquía absoluta (1814-1833). Alicante, Instituto de Cultura Juan Gil-Albert, 1993. Pero se hace preciso ampliar los territorios estudiados y descubrir nuevas aplicaciones de sociabilidad aparecidas en otros espacios.
} 
continuidad. Al contrario de lo que sucederá después en la Restauración, donde la estabilidad y el turno permitían alimentar bien a las clientelas y consolidar redes de élites de cierta regularidad y duración, no fue posible lograrlo en el pequeño paréntesis gaditano, ni siquiera volver a intentarlo en el Trienio. El momento más oportuno y que debiera haber servido de primer escenario de formación de élites (en el doble sentido de construir grupos estables de parlamentarios por un lado y por otro de educarlos en una cultura política que se habituara a actuar dentro del marco constitucional y aprendiera a practicar la cultura de la representación) fue el periodo de las regencias. Pues bien, desgraciadamente, la hipótesis de trabajo que podemos adelantar es que tanto las condiciones gaditanas y del Trienio como las circunstancias de las regencias, no fueron nada propicias para esa doble formación generacional y cultural de las élites. Y la primera constatación de precariedad en este sentido se refiere a la ruptura, tanto generacional como sobre todo cultural, de la generación gaditana y veinteañista, que podríamos denominar bajo el impreciso calificativo de revolucionaria, con la generación treintañista que ha comenzado a recibir ya el apelativo de generación post-revolucionaria. En efecto, a pesar de cuanto pudiera parecer por la presencia continuada de algunos líderes y por la nueva puesta en vigor de la Constitución del 12, la cultura política de la regencia, salvo pequeños paréntesis, sirvió para revisar el legado gaditano y reorientarlo hacia unas coordenadas moderadas y postrevolucionarias, se impuso el doctrinarismo pactista urgido en buena medida por la guerra civil subyacente.

Repasaremos a continuación los ejes principales que condujeron los primeros pasos del Estado constitucional entre 1833 y 1843 y comprobaremos en ellos cómo las arriba mencionadas lecciones de cultura constitucional no respetaron los principios teóricos de esa misma cultura y, sobre todo, sufrieron en su aplicación agresiones violentas y distorsiones causadas por elementos extraños al sistema. Así un Estado constitucional en pañales, débil y vulnerable no representó un marco adecuado para la formación de las élites en su nueva cultura. Un sentido de Estado fragmentado y vulnerado por influencias extra-constitucionales no consolidó unas élites como únicas intermediarias entre él y la sociedad. Un sentido de la ciudadanía y de los derechos fundamentales incapaz de reconocer como civil el derecho político, torpe a la hora de articular y complementar lo privado y lo público, lo general y lo particular, dejó a las élites desarmadas para actuar como intermediarias entre el Estado y la sociedad. Una ordenación del territorio débil y una creación de espacios políticos desarticulados, influyeron en una cultura provincialista y localista de la élite con un endeble sentido de Estado. Una constante interferencia de mediatizaciones ajenas al sistema constitucional, bien fueran externas o internas, formó a las élites en una cultura de relativismo y debilidad constitucional que está en la base de la inestabilidad futura del sistema. Una rudimentaria concepción de la representación habituó a las élites parlamentarias a desequilibrar fuertemente su papel de intermediarias entre el Estado y la sociedad con el censitarismo, el localismo y el falseamiento electoral. Finalmente una vivencia limitada de los partidos habituó a las élites a una sociabilidad política carente de cohesión y de ideología, incapaz de generar élites potentes con liderazgo para hacer participar a la sociedad.

\section{El vulnerable sistema constitucional dificulta la formación de las élites}

\section{Una transición frustrada}

Las llamadas revoluciones de los veranos del 1836 y 1840 se debían, más que a la fuerza movilizada de una sociedad cambiante, a la extraordinaria debilidad y vulnerabilidad del Estado y del sistema político. La llamada transición del Antiguo Régimen al Estado Liberal en estos años no nació del pacto desde dentro del sistema, sino de una ruptura extrasistema y violenta, de ingerencias ajenas y rupturas internas que imposibilitaron la construcción de un Estado constitucional e impidieron su propia consolidación como élites políticas dotadas de una nueva cultura constitucional. Las rupturas fueron constantes, entre constitucionalistas y realistas, y tras la victoria violenta de aquéllos, entre dos facciones, no tanto ideológicas, cuanto estratégicas de 
acceso al poder. Además, los constitucionalistas no utilizaron nunca los sistemas legales previstos en la constitución para alcanzar y ejercer el poder. Al final, un enfrentamiento militar y una violenta discordia civil destruyó el Antiguo Régimen y no construyó un Estado constitucional.

\section{Un débil constitucionalismo}

Alejandro Nieto ${ }^{11}$, a quien seguimos en estos apartados, sostiene que se cerró en falso el apresurado proceso de constitucionalización del Estado durante la regencia y fracasó finalmente. La supuesta modernización y democratización del Estado no pasaron de ser una farsa formal con graves consecuencias posteriores. La percepción práctica del constitucionalismo como norma suprema era muy débil en la cultura política española, nadie la respetaba. El que no ganaba las elecciones acudía a la revuelta y cuando adquiría el poder cambiaba la constitución. Se vivía bajo la tutela de una espada militar. Los gobiernos se nombraban y se destituían en los clubes o en la camarilla palaciega, al margen de la constitución. No existía el sentido de que lo público estaba al servicio de la nación, sino que más bien se entendía como un botín de influencias y sueldos a repartir por el gobierno. Los especialistas hablan, pues, de un Estado seudoconstitucional, no se respetó deliberada y sistemáticamente la constitución, lo constitucional en la teoría fue un simple verbalismo y en la práctica una farsa en la que colaboraron con igual cinismo todos los partidos. Como decía El Correo Nacional ${ }^{12}$, los gobiernos representativos actuales son una falaz mentira.

\section{Un Estado vulnerable, pendiente de mediatizaciones extraconstitucionales}

La debilidad del Estado era constante, había otros hombres, según Fontana, que gobernaban a los que gobernaban, existían una serie de dramáticas mediaciones que colocaban casi siempre la toma de decisiones fuera del Estado. Todos sabían que la verdadera discusión del poder se realizaba al margen de esas reglas ${ }^{13}$. Mediatizaban al Estado desde fuera los embajadores y acreedores europeos, y desde dentro el poder de "palacio" en forma de camarillas. Era enorme la influencia de las sociedades secretas y los clubes, donde se cocían motines callejeros, conspiraciones y hasta cambios de ministros. Nieto ${ }^{14}$ concede a las Juntas provinciales revolucionarias, bajo la denominación de "revolución provincial", la mayor mediatización hasta tanto que cree que anularon el poder del Estado. Cambronero ${ }^{15}$ resumía los tres primeros gobiernos del sistema liberal de la regencia diciendo que el primero cayó por la guerra, el segundo sucumbió por las juntas populares, el tercero por una sedición de soldados, y cabe añadir que el cuarto por otra combinación de juntas y generales. Porque los militares fueron el influjo extraconstitucional más importante, cada partido y cada gobierno tuvo un general como valedor. El culmen de la tutela militar llegó a anular el sistema, cuando en 1838 ocupó el gobierno y en 1840 el Estado. Por otra parte, la Milicia fue otro gran agente de distorsión del funcionamiento de las decisiones del Estado, tomadas en la calle por un motín de doscientas personas. Creada inicialmente como contrapeso militar para sostener la constitución gaditana frente al monarca o al ejército, luego se dedicó a derrocar gobiernos movida por los intereses políticos del partido que tenía dificultades de acceso al poder ${ }^{16}$.

Pero tal vez fue la guerra el elemento extraconstitucional que más desfiguró la construcción del Estado constitucional en sus primeros tiempos y que más obstruyó la formación de sus élites. Ya la de la Independencia dividió a las élites en España, una parte de las clases

\footnotetext{
${ }^{11}$ Alejandro Nieto, Los primeros pasos del Estado Constitucional. Historia administrativa de la Regencia de María Cristina de Borbón. Barcelona, Ariel, 1996, 12.

${ }^{12}$ El Correo Nacional de 25/07/38.

${ }^{13}$ A.Nieto, Op.cit., 40.

${ }^{14}$ Ibid, 41 .

${ }^{15}$ DSCD, del 26/11/38.

${ }^{16}$ A.Nieto, Op.cit.,100.
} 
cultas y superiores españolas se colocaron del lado hispanofrancés y otra del lado hispanoinglés. Este trasfondo bélico dificultó las posibilidades de reproducción de la élite, como demuestra el hecho de que la generación del ocho tuvo muy poca capacidad de pervivir como élite política y de actuar como sujeto de poder más allá de 1820. La otra guerra civil, la carlista, no fue menos influyente a los efectos de formación de las élites que perseguimos. Porque funcionaron en estos siete años dos Estados diferentes en España, dos élites que ejercían sus funciones cuando su bando ganaba ${ }^{17}$.

\section{Un Estado formado de apariencias y falseamientos}

Otra rémora de los primeros pasos del Estado fueron los falseamientos del sistema, muchos de ellos provocados desde dentro del mismo por los propios protagonistas políticos. Nieto ${ }^{18}$ sitúa estos falseamientos en tres áreas: en el funcionamiento de las Cortes, en el equilibrio constitucional de poderes y en las actuaciones judiciales. Para nuestro propósito esta observación es de capital importancia, porque está situando la responsabilidad de este fracaso político en las propias élites que lo lideraron, en los partidos y los gobernantes que lo protagonizaron. Las contradicciones de los sistemas y las élites políticas vienen de atrás, ya Cádiz había alimentado unas élites efímeras que no pudieron ejercer el poder con las normas que estaban elaborando, fueron más intelectuales que políticas, más teóricas que prácticas, más legislativas que ejecutivas, capaces de crear normas pero inexpertas en aplicarlas. La ausencia de aplicación es una mala escuela de élites, porque donde realmente se conforman éstas y consiguen desarrollar toda su virtualidad es en el ejercicio del poder, en la gestión de la influencia, en la toma de decisiones. Y fue precisamente en esta función en la que fueron habitualmente desplazadas por otras fuerzas que actuaban desde fuera del sistema. La primera paradoja de las élites gaditanas es que no fueron elegidas, la mayoría de los representantes de la nación -tanto peninsulares como americanos-, fueron autoproclamados, no delegados del pueblo ni de su provincia, sino designados o cooptados. Pero cuando las élites tuvieron la primera oportunidad de aplicar la teoría del Estado constitucional, en la regencia, es cuando padecieron más mediatizaciones y se desviaron más de su trayectoria constitucional. Los primeros pasos del Estado constitucional reflejan las enormes paradojas y vacíos de cultura política que padecieron las élites españolas estos años.

\section{La imprecisa definición de la ciudadanía y su precaria aplicación}

Las relaciones del Estado con los ciudadanos no se basaban precisamente en el reconocimiento universal de los derechos fundamentales, sino en la interesada argucia que distinguía entre derechos civiles y políticos. Se entendían los llamados derechos políticos como concesión del legislador. Como explicaba el procurador Sancho ${ }^{19}$ : "Los derechos se dividen en civiles y políticos. Los civiles son de todos, corresponden a todas las edades, sexos, ricos y pobres, grandes y pequeños, son inherentes a todas las personas que existen en la sociedad. Los derechos políticos dependen de las disposiciones de la ley, ésta los da". El procurador Alday ${ }^{20}$ sostuvo que también "los derechos políticos se basaban en la sociedad y eran derivados de ella misma, pero su uso no era conveniente para todos a un tiempo, y por eso, aunque han nacido de la sociedad misma, sale de las leyes el modo de usarlos".

Tampoco los que ellos denominaban derechos civiles se respetaban habitualmente. El reconocimiento y garantía de las libertades políticas, de los derechos del hombre y del ciudadano, se proclamaron de una manera formal, no en el Estatuto pero sí en la constitución del 12 y en la

\footnotetext{
${ }^{17}$ Ibid..., 102.

${ }^{18}$ Ibid..., 41.

${ }^{19}$ DSC, 1836 , III, 78.

${ }^{20}$ DSC 1836, III, 197.
} 
del 37. Pero una cosa es el reconocimiento formal y otra el respeto real, en efecto, aquel Estado constitucional nunca respetó los derechos fundamentales. Fueron ignorados siempre, tanto por los gobiernos, como por el aparato político y por las fuerzas armadas, con el agravante de que tampoco los jueces y tribunales llegaron a poner remedio a este incumplimiento ${ }^{21}$.

\section{La conflictiva creación de los nuevos espacios políticos del Estado descoloca a las élites}

\section{El territorio pasa de ser un ámbito administrativo a ser un espacio político}

Aparte de las razones administrativas y fiscales que el Estado liberal tenía para articular y ordenar el territorio, existen también otras de tipo político que fueron las que afectaron al comportamiento de las élites. El territorio pasa de ser un ámbito de mera gestión administrativa a formar un espacio de naturaleza política. Y no tanto en el sentido de la traslación de órdenes emanadas desde el poder central a las esferas provincial y municipal, sino en el sentido más propio de formar parte de una nueva cultura política. Y dichos espacios políticos se refieren, no sólo al ámbito territorial en el que ejercen el poder político esas autoridades, sino también a la ordenación política del espacio en el que participan electoralmente los ciudadanos y al que se sienten vinculados los representantes de esos ciudadanos. Desde este momento el territorio adquiere también un valor y un contenido político que las élites parlamentarias han de aprender a administrar.

En el periodo de la regencia, la creación de estos diferentes espacios políticos, tanto del poder ejecutivo, como del legislativo y judicial, experimentan un apasionante proceso de innovación y exploración, pero también de fuertes tensiones. Ahora nos ocuparemos de los espacios de la provincia y del municipio, ámbitos donde desarrollan las élites su actividad de representación y donde establecen su contacto con la sociedad representada. Esta vinculación con el territorio es muy importante en la comprensión de las élites, porque tiene un doble componente muy fuerte, tanto de procedencia y pertenencia a un territorio como de vinculación a la propiedad de la tierra. Es justamente en el valor primario y natural de la territorialidad donde las élites nutren sus intereses y en ese ámbito de la tierra donde establecen las relaciones sociales y patrimoniales que les permiten configurarse como élites de influencia y de poder. Más adelante, en el epígrafe dedicado al parlamento y al ejercicio propiamente del poder legislativo, nos ocuparemos del espacio político del distrito, que también nace ahora como escenario donde arraiga el poder de las élites y de donde directamente extrae el apoyo de los ciudadanos en forma de votos. Todos estos espacios políticos son escenarios de poder, son materiales de los que se nutre la identidad de las élites. Las vicisitudes de su definición y estructuración durante la regencia influyeron en la cultura política de las élites y en su manejo de las dimensiones territoriales del poder político.

\section{La entrada de "la política" en la actuación de las autoridades}

Es preciso decir que la cultura política del antiguo régimen, incluso la de la ilustración, no contempla "la política" como una actividad propia ni de las autoridades ni de la sociedad, será una creación del liberalismo. El paréntesis ilustrado de Javier de Burgos y su Instrucción de 1833 era aún una solución antigua, a base de autoridades militares, intendentes de rentas, subdelegados de fomento. Porque en el Antiguo Régimen los súbditos no podían tener intención política sin ser subversivos, por eso las autoridades sólo debían controlarla y reprimirla, nunca incentivarla. Ni incluso ellas mismas tenían pretensiones políticas, porque su misión no iba más allá del mero fomento. Por eso el ilustrado Burgos sólo proponía administrar bien, no quería que los subdelegados de fomento fueran autoridades políticas, sino que fomentasen la prosperidad del

\footnotetext{
${ }^{21}$ A.Nieto, Op.cit..., 67
} 
país. Es decir, las élites no podían hacer política, porque ese quehacer estaba confiado a la autoridad judicial y a sus cuerpos.

Importa saber, pues, que es exactamente en estos momentos cuando se descubre "la política", cuando las autoridades del Estado constitucional asumen "la política" como propia de su actividad. Ahora es cuando los jefes provinciales y los alcaldes pasan de darle un contenido sólo administrativo a su actuación pública, a imprimirle un sentido también político. Se hace necesario crear unos nuevos espacios políticos donde esos nuevos sujetos políticos puedan actuar políticamente. Se está produciendo un cambio importante en la cultura política, el "hacer política" comienza vagamente a definirse como un derecho del ciudadano y una obligación de la élite, a ésta la confiere poder, y a aquél capacidad de participar en política. Está sentándose justamente uno de los fundamentos de la función de las élites políticas, la misión de las autoridades consistía en representar y actuar de acuerdo con la política estatal, y al mismo tiempo en controlar las actividades políticas de las corporaciones y en gestionar la participación de los ciudadanos. En el mismo proceso en que nacen las funciones políticas de los gobernadores provinciales / jefes políticos, en definitiva de las autoridades intermedias, se están abriendo las capacidades de influencia y de liderazgo político de las élites.

Estamos en los albores de la política, como se comprueba por el debate que suscita entonces el concepto de "político". La diferencia entre lo político y lo administrativo no estaba aún del todo clara, éste significaba gestión de intereses y aquél agotaba su contenido inicial en lo opuesto a lo militar. Así lo expresa el teórico moderado Oliván ${ }^{22}$ cuando explica el adjetivo de "político" añadido a sustantivo de "jefe": "No debiera llamarse político porque, aun iniciado en el pensamiento del gabinete y siempre dócil a su impulso, no tiene otras funciones más que las administrativas. ... Lo político se refiere al régimen del Estado y no a la administración del país: entre nosotros el adjetivo político se ha usado en la contraposición a lo militar en tiempos en que no se discernía bien lo administrativo; y ahora que todo se ha ensayado, se ve y sabe que el orden político en la monarquía constitucional no cae bajo la autoridad de los funcionarios públicos, por más que la ley les confiera alguna atribución formularia". Por su parte, el propio Javier de Burgos $^{23}$ no lo entendía y era sincero cuando decía que "era desacertado el título de jefes políticos, pues les corresponde más bien la policía que la política, y del sustantivo policía no se forma el adjetivo político. Hay que evitar determinadas actuaciones de trascendencia política: debe prohibirles la ley hablar de sí mismos en sus comunicaciones, hacer alarde de sus principios u opiniones particulares, desenvolver la teoría de su administración y, por consiguiente, publicar programas o alocuciones".

En esta misma dirección del nacimiento de la naturaleza política de la acción de las élites locales, cuando se hablaba de los ayuntamientos, acuñaron dos conceptos para explicar este cruce de la política, expresada en la frase gobierno político, con la administración reflejada en el dicho gobierno interior de los pueblos. Nieto cree que ambos debían coincidir en el ayuntamiento, de forma que el alcalde y el corregidor era representante del gobierno político y de la gestión de la justicia, mientras que los regimientos de los concejos y los concejales sólo eran administradores, reguladores de la vida económica del municipio, denominada como gobierno interior. En el municipio se anudaban así dos líneas diferentes, por un lado la que venía de abajo arriba, la de los concejales en cuanto representantes de los pueblos, que se expresaba como gobierno interior o económico. Y por otro lado, la que venía de arriba abajo, encarnada en los órganos de poder ejecutivo, el alcalde y el jefe político provincial, que se expresaba en el concepto de gobierno político.

En este mismo debate sobre la naturaleza política de las actuaciones de las élites locales, apareció también entonces por primera vez, aunque de forma muy rudimentaria, el concepto de "pueblo" con un contenido específicamente político. Lo expresa Nieto ${ }^{24}$ diciendo que el Estado

\footnotetext{
${ }^{22}$ Oliván, De la Administración Pública, reedic. de García de Enterría en 1954, pág.141.

${ }^{23} \mathrm{~J}$. de Burgos, Ideas administrativas..., 91.

${ }^{24}$ A.Nieto, Op.cit..., 296.
} 
de la monarquía española se estructuraba durante la regencia en tres niveles, el primero y sujeto básico era la nación que actuaba a través de sus poderes constitucionales, el tercer nivel era el ayuntamiento, que representaba al sujeto de las unidades particulares en el "pueblo", y en medio se hallaba la provincia, que oscilaba entre los dos anteriores. Pues bien, ese concepto de "el pueblo" no era sólo una realidad social (agrupación de personas que convivían en un mismo término), sino también política (como la nación) e incluso jurídica, puesto que era titular de un patrimonio y, en su caso, de obligaciones. Así pues, se utilizaba la palabra "el pueblo" para expresar un concepto aún impreciso de contenidos sociales, políticos y jurídicos.

Pero de esta entrada de la "política" en la actividad de las autoridades e incluso de este concepto político de "el pueblo", durante la regencia, no debemos extraer conclusiones precipitadas. De hecho, las élites no alcanzaron un verdadero sentido innovador de actuación política, una vocación de gestionar el poder y una naturaleza representativa. Porque este énfasis político que comentamos se puso siempre en el órgano unipersonal que representaba al poder central, mientras al órgano colectivo que representaba a la sociedad sólo se le reconocía una función administrativa o de gobierno interior. Es decir, se concede naturaleza política al poder que baja de arriba abajo, desde el ejecutivo hacia la sociedad, pero se concede un valor meramente de fomento y administrativo, no político, a los que recogen la representación desde debajo de los intereses locales, sean provinciales o municipales. Con ello no se estaba reforzando el carácter político de la representación de las élites intermediarias, sino la naturaleza política del control por parte del poder central. Sí es verdad, sin embargo, que introduce un componente nuevo en la cultura política, el reconocimiento de la naturaleza política de la actuación de las autoridades, antes inexistente, y un tímido reconocimiento del pueblo como sujeto político.

\section{El debate artificial sobre el centralismo}

El debate centralismo / descentralización, aunque tiene relación con este paso de las élites de administrativas a políticas, sin embargo, tal como se planteó en la regencia no permitió profundizar su cultura política nueva. Porque la pugna entre centralismo moderado y descentralización progresista fue un tanto artificial en esta etapa española. Los radicales sólo apostaron por la descentralización cuando no podían acceder al poder central y se tenían que contentar con los poderes descentralizados de juntas, provincias y ayuntamientos. Unos exigían demasiada autonomía, los otros demasiado control, no consiguieron consensuar qué contrapoderes al gobierno debían actuar en los territorios. En este cruce de intereses, las élites no se movían tanto por concepciones del Estado o programas de los partidos, sino por la mera táctica de acceder al poder. Las élites aprenden que deben ser centralistas cuando están en el poder y apoyar la descentralización cuando están en la oposición. El Estado centralista fue sólo una ficción, y el programa descentralizador sólo una estrategia para desalojar del poder al contrincante.

\section{Del provincialismo a las provincias, del subdelegado de fomento al gobernador civil}

Los especialistas ${ }^{25}$ suelen denominar "provincialismo" a las pretensiones localistas de las provincias históricas preconstitucionales. Pero hubo otro provincialismo postconstitucional que llegó a plantar cara al propio Estado. La cultura revolucionaria gaditana establecía que "el gobierno político de las provincias residirá en un jefe superior, nombrado por el rey en cada una de ellas". Desarrollan esta idea luego la Instrucción de 1813, la de 1823 y el arreglo de 1835. Desde entonces los subdelegados de fomento se convierten en gobernadores civiles, y en 1836 vuelven los jefes políticos gaditanos, que antes no habían llegado a funcionar. Para nuestro interés de la cultura política de las élites, hay que retener que es el momento en que los liberales

${ }^{25}$ A.Nieto, Op.cit..., 280 
convierten la actividad de estas autoridades provinciales en una acción de naturaleza profundamente política, y dejan como residual su actividad administrativa. La obsesión política liberal al definir al jefe político fue centrarla en el orden público y en el control de los ayuntamientos ${ }^{26}$, y culminará aproximando los jefes políticos o gobernadores a las Diputaciones $\mathrm{y}$ al poder militar.

\section{Las Diputaciones: del interés provincial a la rebelión de las Juntas}

Esta cultura gaditana estaba impregnada de una concepción dialéctica de la administración provincial y municipal. Tal herencia subsistiría en las versiones posteriores, aunque con el énfasis en uno u otro polo según etapas. Una tensión bipolar que se produce, no sólo entre poder central y provincial, o entre el provincial y el municipal, sino interiormente entre la Diputación y el jefe político y también en el interior del municipio entre el ayuntamiento y el alcalde. De forma que el gobernador representaba al gobierno y actuaba de correa de transmisión que iba de arriba abajo, y la Diputación representaba a los intereses de los pueblos, que transmitía de abajo a arriba. Y paralelamente, el alcalde es un mero peón del gobernador civil y el ayuntamiento representa a los pueblos.

El debate se establecía entre las peculiaridades localistas y el uniformismo jacobino; mientras en el primer momento revolucionario, el balance se inclinó hacia los centralistas, en el segundo momento postrevolucionario, después del breve paréntesis ilustrado de Javier de Burgos, se impuso el protagonismo práctico de las provincias. Desde el verano de 1835, la fuerza provincial se rearma y, tanto Diputaciones como sobre todo Juntas, acuden a la violencia y se imponen en lo que se ha denominado ${ }^{27}$ la rebelión de las provincias. Sabemos que Mendizábal pacificó a las Juntas convirtiéndolas en Diputaciones y las dotó de ciertas competencias que se habían adjudicado las Juntas de armamento. La rebeldía provincial en combinación con la guerra carlista paralizó el desarrollo del Estado constitucional y casi lo disuelve. Este hecho no habituó precisamente a las élites políticas a ejercitarse en la cultura de la representación parlamentaria, puesto que el primer burlado por la actuación de las Juntas era el parlamento. Las Juntas revolucionarias fueron las que ocuparon el único espacio de contrapoder central y dieron a las Diputaciones un sentido político revolucionario, una carga de intereses provinciales, y debilitaron su dependencia del jefe político ${ }^{28}$.

\section{Los Ayuntamientos: entre los intereses de los pueblos y el control del gobierno}

Tampoco la experiencia municipal fue un buen escenario para la educación de las élites durante la regencia. De entrada fue un fracaso político, porque la contraposición de los dos modelos fue estéril y llevó en varias ocasiones a romper la baraja del Estado constitucional. Por otro lado, ésta que podría haber sido considerada como una escuela de cultura política para las élites, fue más bien un escenario donde no primaron las ideas y la concepción del Estado, sino la inmediatez táctica del acceso al poder. Las élites no consiguieron aprender en este ámbito cuál era el papel del Estado y cómo debían representarse los intereses de los pueblos, como se decía entonces. Subordinaron reglas e instituciones al inmediato acceso al poder, falsearon los valores de la participación y la representación política. Seguramente que era en los ayuntamientos donde las élites debían haber aprendido los nuevos hábitos del Estado constitucional, el uso de unos espacios políticos creados precisamente para este fin, para facilitar la participación política y para experimentar su calidad de representantes y de actores políticos. En definitiva, las élites fueron causa y efecto de este fracaso, al tiempo que no se adiestraron en el manejo de este instrumento

\footnotetext{
${ }^{26}$ Ibid..., 247, 259.

${ }^{27}$ Ibid..., 271

${ }^{28}$ Ibid..., 107. 291.
} 
ni consiguieron modernizar su cultura política, deformaron el instrumento mismo y contribuyeron a otro falseamiento más en los primeros pasos del Estado constitucional.

\section{Los límites impuestos a las élites locales}

Como hemos visto, la parte representativa de Diputaciones y ayuntamientos no estaba configurada propiamente con una naturaleza política, que sólo tenía el jefe político y el alcalde, sino con mera función administrativa y gestora de los intereses locales. Las élites locales desprovistas de esta función política carecían de interés, desde el momento en que les alejaban de la capacidad de tomar decisiones y de ejercer el poder. Por otro lado, tanto los jefes políticos como los alcaldes, a pesar de la naturaleza política de su poder, tenían unas serias limitaciones y se recortaban sus atractivos.

Por lo que se refiere a los jefes políticos, a pesar de todo el énfasis de concentrar la única autoridad política y de orden público con que estaban diseñados, fueron bastante inoperantes de hecho durante la regencia. Podían cesarles fácilmente, eran cambiados frecuentemente de provincia, y sobre todo actuaban dóciles a las Juntas revolucionarias, cuando no eran asesinados por ellas. Como dijo Seoane ${ }^{29}$ en 1838 , los gobiernos políticos nada hacen porque nada pueden hacer, son muebles inútiles en las provincias y aun objeto de desprecio, sus nombramientos se han hecho con poco escrúpulo y han caído en descrédito.

Y los alcaldes, por su parte, estaban sometidos a una dependencia jerárquica muy rigurosa, debían obedecer y ejecutar las órdenes del feje político. Además de esta dependencia política estricta, el ejercicio de la alcaldía ofrecía durante la regencia algunos problemas importantes nacidos de su penuria económica. Al estar los ayuntamientos encabezados, el reparto del cupo ofrecía una posibilidad de abusos gravando más a los enemigos e eximiendo a parientes o amigos. Por otra parte, se podía declarar insolvente al ayuntamiento que no podía recaudar el cupo exigido y responsable personal de la deuda al alcalde. El dilema era la dureza en la recaudación, lo que era su ruina política, o el pago de la deuda, lo que era su ruina económica. Muchos se resistían a entrar en los ayuntamientos, no había competidores en la elección, había que obligarles como mayores contribuyentes ${ }^{30}$.

Los concejales, aunque su elección era más censitaria, padecían corruptelas y conflictos a la hora de poder ser designados alcaldes. Olózaga ${ }^{31}$ decía que los secretarios de los acuerdos, que seleccionaban al alcalde de entre los concejales de las ternas, eran una tienda de venalidad de los cargos municipales, un tráfico escandaloso en las elecciones de los ayuntamientos, de forma que en determinadas épocas y provincias se podría asegurar cuánto dinero costaba el ser o dejar de ser alcalde.

Las elecciones municipales fueron menos restringidas, con el Arreglo provisional de 1835 el cuerpo electoral alcanzó el 30\% del total del censo, lo que multiplicaba por diez la cuota de las elecciones a Cortes ${ }^{32}$. Sin embargo, ni moderados ni progresistas querían el sufragio universal para elegir a los concejales, se diferenciaban en mayor o menor censitarismo. Y cuando los progresistas ampliaban el censitarismo, no era por razones de participación, sino para asegurarse una ventaja electoral en las grandes ciudades ampliando la base del censo a las clases medias que creían sus partidarias. Incluso, no exentos de cinismo, decían que no querían incluir a los jornaleros porque, al estar mandados por el terrateniente, votarían a los moderados.

\footnotetext{
${ }^{29}$ DSCD , 15/11/1838, 59.

${ }^{30}$ A.Nieto, Op.cit...,311.

${ }^{31}$ DSCD, 13/4/1840, 76.

${ }^{32}$ A.Nieto, Op.cit..., 313, 351.
} 


\section{El precario parlamentarismo no permite a las élites madurar en la cultura de la representación}

Los borrosos límites de la actividad parlamentaria confunden los perfiles de las élites

La regencia de María Cristina tuvo una actividad normativa muy indefinida e irregular. Fue brusca, con vueltas atrás, recuperando constituciones y leyes derogadas, y habitualmente violenta. Nieto sostiene que se emitieron normas ilegales, disposiciones espúreas (emanadas de autoridades militares, de juntas revolucionarias, de cabecillas carlistas). Era frecuente alterar la jerarquía del procedimiento, pasar una circular ministerial por encima de una ley aprobada en Cortes. Además, era general la no aplicación o el incumplimiento de las mismas, con la complicidad de las autoridades provinciales o locales.

Las Cortes ejercían actividades no normativas, realizaban debates, interpelaciones, mociones de censura, peticiones, facultades, contestación al discurso de la Corona, que contribuían a la formación de la cultura política de las élites. Seguramente el control político del ejecutivo era uno de los reductos más interesantes para la formación de las élites parlamentarias, cuando podían entrenarse en la nueva cultura del debate político, de la crítica al gobierno, de lo que Alcalá Galiano ${ }^{33}$ llamó "la ciencia de gobernar que se necesita en estos cuerpos, pues aunque su objeto principal sea hacer leyes, tienen una gran parte en el gobierno del Estado". Quizás la contestación y el debate del discurso de la Corona era la actividad más propia de la cultura política de la élite, porque se trataba de un verdadero programa político del gobierno donde se hacía un balance del anterior y una discusión donde se practicaba la ciencia de gobernar y el juicio político.

En este momento de indefinición y de aprendizaje, no estaban claras las fronteras entre legislativo y ejecutivo, no acertaban a distinguir entre legislar y gobernar, se entrometían constantemente en labores de administración, entrando a veces en colisión con otros órganos de gestión. Era frecuente que en los momentos de actividad parlamentaria el ejecutivo disminuyera su acción, en cambio, para que recuperara todo su espacio político y administrativo necesitaba que las Cortes estuvieran cerradas.

\section{El irregular funcionamiento del Parlamento acostumbró a las élites a los falseamientos}

Pero predominó un ambiente de cierta falsedad e insinceridad en el Parlamento. Cuando la mayoría estaba asegurada se saltaban trámites y se cometían las irregularidades más inauditas, y si se perdía una votación se repetía tan pronto como había suficientes votantes. Innumerables sesiones dedicadas a revisar denuncias, actas protestadas e irregularidades electorales que ya indicaban el precario funcionamiento de un sistema electoral inexperto y condicionado por todo tipo de fuerzas y presiones extraelectorales. No hay constancia de unas elecciones que puedan considerarse limpias. Habrá pocas cuestiones sobre las que se muestre mayor unanimidad entre testimonios de la época e historiadores posteriores ${ }^{34}$, por lo que no entraremos aquí en estos detalles.

Sobre los empleados públicos -diputados y al tiempo funcionarios del gobiernofrecuentemente recayó la sospecha de compra de votos. Se comentaba en los mentideros parlamentarios en 1836 que a doce mil reales. Como entonces no existía retribución de los diputados, había que exigir como única garantía de su independencia que tuvieran suficiente riqueza personal. Esta era una poderosa disculpa de los moderados para restringir cada vez más

\footnotetext{
${ }^{33}$ DSCD,1643, del 12-5-1840.

${ }^{34}$ Más arriba hemos citado las obras de Isabel Burdiel, M.Cruz Romeo, y entre nosotros lo ha estudiado Margarita Caballero, El sufragio censitario. Elecciones generales en Soria durante el Reinado de Isabel II. Junta de Castilla y León, Avila, 1994.
} 
el censitarismo pasivo entre los elegibles. En 1836 se elevó el requisito de renta para ser elegido hasta seis mil reales, pero pareció ${ }^{35}$ insuficiente porque tal cantidad no podía garantizar la independencia del diputado, "seis mil reales no dan sino para hacer el viaje a Madrid desde algunas provincias y, llegado el diputado que cuenta sólo con ellos a la Corte, se halla sin una peseta y obligado a prostituirse al poder; sí, prostituirse, porque lo primero es satisfacer las necesidades"

Otra presión importante sobre las cámaras provenía de las tribunas, donde el público asistente formaba con demasiada frecuencia alborotos y altercados que se intuyen en los Diarios de Sesiones ${ }^{36}$. Solía pagarse a grupos de jóvenes bien presentados para que apoyaran estrepitosamente a los diputados ministeriales o a los propios ministros en sus intervenciones, y sobre todo, para que abuchearan a la oposición al gobierno. No estuvieron ausentes otros gestos irregulares, como la actitud tendenciosa de los presidentes de las cámaras dirigiendo las discusiones o infiriendo tratos discriminatorios a los oradores desafectos, salidas de tono verbal, e incluso agresiones físicas.

\section{El sistema de múltiples confianzas colocaba al parlamento bajo extrañas dependencias}

Ya es conocido el sistema de múltiples confianzas en que se basaba el régimen constitucional liberal. Fueron precisamente los parlamentos de regencia, desde el Estatuto hasta la Constitución del 37, los que iniciaron este sistema de contar primero con la doble confianza. La que el rey debía tener en las Cortes, imprescindible porque convocaba y desconvocaba, y la que el Parlamento debía tener en el monarca y en el gobierno que había nombrado. Era precisa una tercera, la llamada confianza de pueblo, factor inédito que entorpecía el arbitraje de la Corona sobre el parlamento y el gobierno, que dependían de que los ayuntamientos más grandes, provincias y juntas aceptaran al gobierno, o se rebelaran contra el poder central hasta derribarlo fácilmente. Hay autores ${ }^{37}$ que creen que estas instancias turbulentas y anárquicas coaccionaron la prerrogativa regia y sustituyeron a las instituciones parlamentarias en el sistema. Se complicó más este inestable equilibrio entre el parlamento y el gobierno bajo el arbitraje de la Corona con la aparición de una cuarta confianza, la del ejército y la milicia. Y aún cabe hablar de una quinta y sexta confianzas, que tenían que otorgar otros agentes extraconstitucionales con un peso excesivo en las decisiones del sistema, como la de los clubes, camarillas, embajadores de Inglaterra o Francia, o acreedores de la Hacienda. Semejante exigencia de siete o más confianzas coincidentes era imposible durante mucho tiempo, bastaba que fallara una para que el proceso de un cambio de gobierno volviera a comenzar. Este es el marco en el que se formaron las primeras élites políticas, donde no pudieron aprender el sentido de Estado, el valor de las elecciones, el significado de la representación, la independencia del poder legislativo, la función de los partidos políticos, la articulación de los espacios generales y particulares en el Estado, la capacidad de liderazgo y de ejercicio del poder de las élites políticas, la función de intermediarias ante la sociedad, o el reconocimiento de la ciudadanía.

\section{El aprendizaje de la movilización política}

Los análisis de la participación política que ha producido la historia política y social se han fijado sólo en aquellas formas de movilización de corte clásico que nos resultan familiares para nuestra cultura política, como son los procesos electorales, campañas, militancia en partidos, programas, mítines y manifestaciones de corte político. Se impone una nueva valoración de las formas de movilizarse desde las perspectivas informales y simbólicas que adopta la historia

\footnotetext{
${ }^{35}$ Gaminde, en la sesión del 14/05/36. DSC, 1836, III, 207

${ }^{36}$ Borrego lo denuncia en El Español n ${ }^{\circ} 146$. A.Nieto, Op.cit...., 50

37 J. TomásVillaroya, El sistema político del Estatuto Real (1834-1836). Madrid, 1968: J.I.Marcuello, La práctica parlamentaria en el reinado de Isabel II. Madrid, 1986
} 
cultural y que atiende a otro tipo de movilización ajena y anterior a la urna. El análisis cultural descubre procesos constructores de movilización en actitudes que aparentemente pertenecen a la vieja cultura política, hay cauces y actitudes tanto formales como informales, no previstos por la teoría clásica, que expresan inquietudes e intereses movilizadores. Entre los formales e institucionales están el proteccionismo, la beligerancia religiosa, la defensa de instituciones locales, la protesta fiscal, la reclamación de abastecimientos, el asociacionismo primitivo, el mutualismo. Pero hubo otros muchos cauces de movilización informales, sobre todo en ciudades pequeñas, como el abandono de la deferencia voluntaria y la petición de compensaciones, la resistencia hasta forzar la coacción, las cuestaciones, fiestas, recibimientos de autoridades. Todo ello indica un cambio de valores, cuestiona los viejos principios tradicionales de la familia, la propiedad, de la costumbre, desmitifica los viejos ritos de la cultura política anterior. Este tipo de movilización es la que hay que descubrir en estos años, en los que particularmente era casi la única manera posible de participar en política, y cuando el valor político de estos gestos era muy superior al actual.

\section{La insegura exploración de las élites sobre la sociabilidad política de los partidos}

\section{Las élites parlamentarias y sus indefinidos espacios de actuación}

Las relaciones entre el ejecutivo y el legislativo, en cuanto a funciones y élites compartidas, eran mucho más intensas probablemente que en etapas posteriores. Sin duda el proceso de separación y especialización de ambos poderes estaba aún en etapas muy iniciales. Los funcionarios eran la cantera más importante de políticos, tanto del ejecutivo como del legislativo. Varios estudios han comprobado que las Cortes para los empleados públicos eran una palestra de adiestramiento y sobre todo una plataforma de lanzamiento de cara a su carrera política. Burdiel ${ }^{38}$ estima que los empleados públicos y oficiales militares ocuparon entre un tercio y casi la mitad de los escaños. Solían iniciarse en política con un cargo provincial (gobernador, intendente, diputado provincial) pero todos aspiraban a la condición de diputado. Fue constante el paso de la burocracia a los escaños, especialmente durante la regencia. Y viceversa, todo gobierno necesitaba contar con un buen grupo de diputados dispuestos a apoyar su causa a cualquier precio. Tales circunstancias explican la enorme proporción de funcionarios que tenían asiento en las Cortes.

Es ahora cuando se descubre el espacio institucional de las élites y el tipo de relación que ellas pueden tener entre sí. Las relaciones de las élites ejecutivas con las parlamentarias se van definiendo desde 1836, cuando se establece que los diputados a Cortes pueden ser nombrados secretarios de despacho, y desde 1837, cuando los ministros pueden ser senadores o diputados y tomar parte en las discusiones de ambas cámaras, aunque sólo tengan voto en la suya. La relación de las élites ejecutivas con el parlamento también se fija y se pone en práctica ahora. Un ministro dedicaba más tiempo a sesiones parlamentarias que a su acción de gobierno. Esta misma acumulación de funciones fue creando la necesidad de desdoblar cargos, como la aparición del subsecretario. Incluso se vio necesario un oficial o un escribiente destinado particularmente a informar al ministro de las discusiones de los cuerpos legisladores y aun de la prensa periódica.

\section{Aprendiendo la sociabilidad política de notables, clubs, facciones, disidencias y partidos}

Cuando aún no funciona el esquema clásico de partido político, en este momento constituyente de la sociabilidad política, las élites tuvieron que ir descubriendo las maneras de coordinar esfuerzos, de enriquecerse con la formación de grupos afines políticamente y las fórmulas de actuación conjunta en las cámaras. Justamente en este momento de descubrimiento y

\footnotetext{
${ }^{38}$ Isabel Burdiel, La política de los notables. Moderados y avanzados durante el Régimen del Estatuto Real (1834-1836). IVEI, 1987, Valencia.
} 
exploración debieron crearse situaciones muy propicias para nuestro análisis cultural de las relaciones informales, de los hábitos y gestos de reconocimiento de grupo, de los códigos de identidad ideológica, de los discursos, ritos y significados propios de los clubs de notables o de los grupos parlamentarios, que estaban llenos de contenidos culturales que apenas hemos comenzado a descubrir ${ }^{39}$.

Necesitamos muchos más estudios sobre la forma cómo se construyen los primeros cimientos de los partidos en los años treinta, especialmente de sus dimensiones más primarias e informales que ahora fueron las más importantes. Se suelen describir los partidos ${ }^{40}$ como una suma de concejales, diputados provinciales y parlamentarios, que forman unos comités, compuestos por propietarios y abogados sobre todo, orientados a conseguir un escaño o un puesto de poder. Estas elementales asociaciones tienen, por tanto, al principio dos utilidades políticas, una que sirve camino de ida para que algunos de sus miembros accedan a una cámara $o$ a cualquier institución de poder local, y otra como vía de vuelta, para que las cúpulas madrileñas y los personajes de la provincia consolidados en ellas consigan formar una red de poder a su alrededor y colocar a sus peones en los distritos. Los hemos visto funcionar como correas de transmisión y ejecutores, no como centros de decisión, de los objetivos pragmáticos inmediatos que conduzcan a un mantenimiento o cambio en el poder. No son laboratorios de programas ideológicos, o espacios para elaborar proyectos de gobierno capaces de diferenciarse entre sí. A lo sumo, en las cúpulas madrileñas de estos partidos se tejen algunas redes, se formalizan pactos, se realizan cesiones y compromisos de futuro para las elecciones.

Sin embargo, los objetivos de nuestra historiografía de partidos siguen siendo bastante institucionales y descriptivos, buscan la diferencia ideológica entre moderados y progresistas, sus prácticas organizativas, el liderazgo que juegan los personalismos en ellos, el origen y expansión de sus facciones y disidencias, o si se reducen a una mera agrupación de práctica parlamentaria. No hemos ahondado aún en los significados y ritos de cultura política que implican, como el valor simbólico de pertenencia a un grupo, la capacidad identitaria de una militancia al margen de la ideología, la sociabilidad de redes horizontales y clientelas verticales que dentro de ellos se producían, o qué etapas y qué largo recorrido se anduvo hasta acabar fraguándose la lejana idea de un partido como vehículo de participación política y de movilización ciudadana. Habrá que estudiar cómo se entienden estas agrupaciones desde abajo, qué nivel de confianza producen en los electores, cuál es su imagen a través de la sátira, la rivalidad, el conflicto, y las campañas, cómo van deteriorando su imagen hasta fin de siglo.

Hay que entender que los partidos de los que se habla en este periodo son el resultado de una deliberada traspolación de la mentalidad actual, o si se quiere, de una comodidad de lenguaje. Porque los partidos en el sentido moderno fueron formándose de manera progresiva de tal manera que quizás no sea lícito hablar de ellos en sentido propio durante toda la regencia ${ }^{41}$. Sociológicamente eran más bien grupos, y políticamente familias y asociaciones de agravios y ambiciones comunes. Burdiel ${ }^{42}$ afirma que la diferenciación sociológica en clases sociales de los dos partidos cada vez se sostiene menos en lo que a su élite política y parlamentaria se refiere.

Superando esa reduccionista contraposición, convendría investigar mejor cómo se fraguan sus respectivas culturas políticas, tanto en lo propiamente programático como en su sociabilidad. Y en este sentido es muy importante el fenómeno de los mutuos préstamos, de las mistificaciones, de las identidades por diferenciación y de las afinidades por exclusión que regían los procesos de formación de los grupos. Desde el punto de vista ideológico, convendría descubrir los topos o lugares comunes de teoría política entonces con gran capacidad de convocatoria, como fue el doctrinarismo francés. Sería necesario averiguar qué atracciones y reacciones provocaron entre las élites políticas los conceptos de revolución o de progreso y cómo

\footnotetext{
${ }^{39}$ Ibid., 58 .

${ }^{40}$ C.Marichal, La revolución liberal y los primeros partidos políticos en España, 1834-1844. Madrid, 1980.

${ }^{41}$ Ibid., 102.

${ }^{42}$ Isabel Burdiel, Op.cit., 78.
} 
ayudaron a diferenciarlas. El papel que jugaron en este camino de identidad entre los viejos doceañistas y los veinteañistas, las experiencias pasadas, el absolutismo que aún estaba reciente, las propias guerras presentes, cómo va desdibujándose el mito revolucionario gaditano, qué precauciones o miedos fueron considerados por cada grupo como pautas que ayudaron a construir su imaginario político, qué prácticas políticas se experimentaron y cómo las entendía cada grupo.

Como decíamos al principio, por lo común, resultan muy explicativas en estos procesos de formación de las diferentes culturas políticas las herencias del pasado, las transacciones con otros grupos, las reacciones contra experiencias fuertes inmediatas, las mitificaciones de viejos legados. Justamente es importante medir el equilibrio entre la capacidad de pacto y la necesidad de ruptura al mismo tiempo que era necesaria en estos momentos fundacionales. En momentos de transición como éste es cuando se debieron realizar enormes esfuerzos por convivir en el mismo marco tres culturas políticas que simultáneamente tenían el reto de sobrevivir y el afán de imponer su hegemonía: los absolutistas, los radicales y los doctrinarios. Exactamente en este trance, propio de los periodos de transiciones, es donde era más necesaria la búsqueda de puntos de encuentro que abrieran caminos para no destruirse mutuamente, y al mismo tiempo la búsqueda de peculiaridades de cada grupo para lograr un hueco propio, un imaginario y un argumentario que los identifique y sea capaz de aglutinar al grupo frente al otro.

Probablemente por esto tuvo tanta importancia, por el lado teórico, el eclecticismo doctrinario que primaba el consenso y la tercera vía que fusiona viejos legados con nuevas teorías. Pero también por otro lado debió ser muy tentador e importante la ruptura del consenso, cierta terquedad política que se impuso como actitud generalizada durante la regencia, de donde proceden todas esas mediatizaciones extraconstitucionales de que hemos hablado. Por el primer lado, se explica el éxito de los términos medios que cultivaba el liberalismo doctrinario, a base de concesiones recíprocas, casi como una gran reconciliación nacional. La propuesta de la doble soberanía, la práctica de la función moderadora de la Corona tuvieron cierto éxito en el periodo, particularmente en la Constitución de 1837. Pero por el contrario, la praxis política no estuvo regida precisamente por este talante de consenso, que fue más bien excepcional $\mathrm{y}$, como hemos repetido tantas veces, se impuso la ruptura de las normas de juego y la agresión desde fuera del sistema. Esta fue, sin duda, una de las causas por las que este escenario debió resultar especialmente difícil para la educación de las élites y especialmente para la implantación de una cultura parlamentaria y representativa que consolidaran el Estado constitucional. 